\title{
LABOURATORY: MAKING WORK AND DIGITALIZATION PARTICIPATORY - INSTEAD OF DISCURSIVELY PLAYING THEM OFF AGAINST ONE OTHER
}

Stefan Sauer, FAU University Erlangen-Nuremberg, Germany

Marco Blank, FAU University Erlangen-Nuremberg, Germany

Sabine Pfeiffer, FAU University Erlangen-Nuremberg, Germany

dx.doi.org/10.18374/JIMS-21-1.4

\begin{abstract}
Digitalization is often thought about only in terms of technical possibilities; the feasibility of its implementation in labor processes and the needs of the latter are given little attention. In our Labouratory, we want to invert this process: to place the focus on the needs of human labor and, with this as point of departure, to ask where and how digitalization can best support and facilitate labor processes.
\end{abstract}

Keywords: digitalization, digitalized labor, labor processes, participatory research, mixed methods 